\title{
Preschool Sibling Interaction in Separated and Married Families: Are Same-sex Pairs or Older Sisters More Sociable?
}

\author{
Cheryl Kier \\ University of East London, U.K. \\ Charlie Lewis \\ Lancaster University, U.K.
}

\begin{abstract}
Two factors have been associated with the quality of sibling relationships: the sex of the children and their family circumstances. Yet the data on each issue are complex. This study examines the sex constellations of sibling pairs in two groups, one of which had experienced a major family disruption (parental separation), with the aim of assessing both influences more fully. Two 1-hour home observations were conducted on 20 preschool sibling dyads of separated parents and 24 pairs in which the parents were married. In both groups the sex configuration of the sibling pairs was important - same-sex pairs seemed to show closer patterns of interaction, and sister-sister dyads were particularly prosocial. These results suggests that previous research showing that older sisters or same-sex pairs interact more are both partly correct. In addition, preschoolers from separated families interacted more. The results suggest that negative life experiences might promote greater closeness between siblings.
\end{abstract}

Keywords: Preschool children, divorce, parent-child interaction, siblings, play, sex roles.

\section{Introduction}

Research over the past 20 years has identified the importance of sibling relationships over the life course (e.g. Boer \& Dunn, 1992; Lamb \& Sutton-Smith, 1982). It is known that preschool siblings spend more time with one another than each does with their parents (Dunn, 1983). Adults maintain close links with their brothers and sisters (Cicirelli, 1994). Yet sibling relationships are also characterised by large individual differences and the goal of much current research is to establish why some children provide support and stimulation to their nearest relatives, whereas others show hostility or indifference (see, e.g., Dunn, Slomkowski, Beardsall, \& Rende, 1994). Two of the major factors that have long been linked with patterns of closeness or distance between siblings are the impact of stressful life experiences on the children and their sex configuration. Yet the data on each of these influences are not completely clear. This study examines these two factors in relation to one another with the aim of discerning their respective and combined impacts upon relationships between preschool siblings. In examining interactions shortly after marital separation it attempts to illuminate the effects of life experiences and the sex constellation of the pair upon their relationship.

Request for reprints to: Charlie Lewis, Department of Psychology, Lancaster University, Lancaster LA1 4YF, U.K.
The first area of research that has been linked with the development of individual differences in sibling relationships concerns the effect of major life stresses, such as parental conflict and separation, upon children. Opinion is divided about how such life experiences might influence sibling relationships. On the one hand it has been claimed that a disturbance such as separation from the parents may draw siblings together. Freud and Dann's (1951) classic observations of wartime orphaned preschoolers described their heightened desire to be with one another and their concern for each other's needs. More recent theoretical analyses have suggested that family members may provide similar support after parental separation, as if to re-establish a balance in family relationships (Beal, 1979). In one-parent households older children may take on many of the father's responsibilities (Schlesinger, 1982) and siblings may give one another more physical contact (Kimball, Stewart, Conger, \& Burgess, 1980), emotional closeness (Robson, 1979; Springer \& Wallerstein, 1983; Troyer, 1979), loyalty (Bank \& Kahn, 1982), or support (Weiss, 1979a, b). Even when a parent is physically present, but is emotionally distant to the children, preschool siblings develop a special closeness (Dunn \& Kendrick, 1982). Thus one hypothesis is that after parental separation, sibling relationships protect children against adversity and would display greater closeness.

However, other data do not support the view that sibling relationships help children to cope with stressful life experiences. It has also been suggested that conflict 
between the parents can spill over into the sibling relationship (Engfer, 1988). Certainly after marital separation parents may be over-burdened (Hetherington, Cox, \& Cox, 1979; Wallerstein \& Blakeslee, 1989) or selfabsorbed (Rohrlich, Ranier, Berg-Cross, \& Berg-Cross, 1977), to the extent that they behave inconsistently with their children, communicate poorly, and can be ineffective in controlling them (Hetherington, Cox, \& Cox, 1982). Research on school-aged children has suggested that sibling relationships might be impaired if their parents' marriage is poor (Brody \& Stoneman, 1987; Jenkins, 1992). Studies of such families after divorce show problems in the sibling relationship (Hetherington, 1988; MacKinnon, 1989). Thus it seems that life stresses, such as living in a disharmonious or divided home, may have complex yet deleterious effects on family relationships. We term this the family pathology hypothesis. To our knowledge there have only been two studies of preschool siblings post divorce and in both cases only one was a preschooler and interaction was observed in the laboratory rather than in the home (Kier \& Fouts, 1989; Summers, Summers, \& Ascione, 1993). Both studies reported differences between divorced and nondivorced sibling pairs. For example, Kier and Fouts' study of boys found greater amounts of play with older sisters in separated than in married families. So the idea that preschool sibling relationships may be under strain after parental separation needs to be examined.

One issue that might make the picture complex concerns the fact that after divorce most children reside with the mother (Hetherington et al., 1992). As the child is deprived of a "male model" (Stolberg \& Anker, 1983), it is often assumed that boys are more adversely influenced than girls. Although this seems not to be the case with older children (Downey \& Powell, 1993), there is evidence to support the view that preschool boys fare worse than girls in mother-headed households after parental separation. For example, Hetherington et al. (1982) found that boys of 4 to 6 years of age from divorced families engaged in less co-operative play and were rated by peers and teachers as being more aggressive than boys from married-parent families. They were also rated as less popular. Girls in the two family types did not show differences in social behaviour to such an extent. Studies of school-aged siblings after divorce have also found that having a boy in the dyad is associated with negative behaviours (Hetherington, 1988; MacKinnon, 1989). It is these observed sex differences that suggest that we should examine the relation between marriage breakdown (a major life stress) and its effects on sibling interaction.

Research on the sex of siblings has revealed two apparently contrasting patterns. One is that girls are more prosocial than boys (e.g. Abramovitch, Corter, \& Lando, 1979; Lamb, 1978a). The other, from research on slightly younger children, suggests that same-sex dyads get along better than different-sex dyads (e.g. Dunn \& Kendrick, 1979). That older girls may be more prosocial has been supported by a variety of studies. Most notable is the home observation of children from 18 months of age with their older siblings, by Abramovitch and her colleagues (Abramovitch et al., 1979; Abramovitch, Corter, \& Pepler, 1980; Abramovitch, Pepler, \& Corter, 1982). Older sisters were significantly more likely than older brothers to engage in prosocial behaviour (including give/share object, co-operate/help, praise/ approval, and give comfort/reassurance) whereas their brothers engaged in a greater proportion of negative interactive bids. Abramovitch et al. (1979, p. 1001) concluded that the older sisters in their sample "seemed to act as "little mothers"".

Comparable patterns were found by two research teams in laboratory observations where the younger one was in the second year of life (Corter, Pepler, \& Abramovitch, 1982; Lamb, 1978a). Lamb suggested that older sisters become more concerned with their siblings' activities and engage in more shared toy play because they are more likely to have been encouraged to take on the role of nurturer. Under stressful conditions in the laboratory (pairs of preschool siblings being left alone together), Stewart (1983) found that older sisters gave much more care than did older brothers to their younger brothers (even when they did not seem to need it). It may be the case, as Lamb (1978a) suggests, that girls are more likely to assume such a caring role when circumstances dictate. However, Stewart's cross-sex care-giving patterns have not been found in studies employing similar methods (Stewart \& Marvin, 1984; Teti \& Ablard, 1989). So, even at preschool age, there seems to be some evidence, although not consistent, that older sisters adapt to the needs of their toddler siblings.

However, other research suggests that a different pattern of sibling relationships (indeed opposite to the one found by Stewart, 1983) is more salient to young children: that same-sex pairs are more prosocial than different-sex pairs. Dunn and Kendrick (1982) acknowledge that older girls may be more sociable as a result of socialisation pressures. However, they found that when the younger child was an infant, same-sex siblings observed at home engaged in a greater number of friendly acts and a lower number of hostile acts in comparison with siblings of the opposite sex. Same-sex siblings also imitated one another more frequently. They found that there were no differences between girls and boys in the behaviour of either the older child or the infant (Dunn \& Kendrick, 1981). We may conclude that further research is needed to examine the same-sex vs. older sister advantage. The examination of siblings in families under stress allows such examination.

The two interrelated aims of this study attempt to bridge some of the issues raised above. First, it examines sibling relationships after parental separation in a sample younger than those previously studied. In this study the children were all preschoolers - a comparable age group to those studied by Abramovitch et al. (1979), Dunn and Kendrick (1982), and Lamb (1978a, b). From the divorce literature reviewed above sibling relationships after parental separation might be expected to show either added closeness (the protection against adversity hypothesis), or impairments (the family pathology hypothesis) after parental separation. Given that stressful circumstances appear to accentuate existing relationship patterns, the second aim is to examine whether divorce highlights the dynamics of preschool sibling relationships. If it does, it enables us to test the two hypotheses described above(1) that older sisters would demonstrate more closeness to their siblings; versus (2) that same-sex preschool pairs get 
on better. As Jenkins (1992, p. 127) claims, "In order to examine whether close sibling relationships act to protect children in stressful circumstances, a research design with a high and low stress group, and statistical analysis allowing one to test for the interaction between the stress and protective factor is needed."

\section{Method}

\section{Subjects}

As part of a larger study on children from separated/divorced and married-parent families (see, e.g., Kier \& Lewis, 1997), 44 infants and their older siblings were observed during free play in their homes. Twenty families were mother-headed due to parental separation, after the couple had lived together on average 4.96 years and separated for a mean of 13 months. The remaining 24 families had both parents living together. They had been living together on average 7.64 years. Participants were recruited from health visitors, playgroups, mother and toddler groups, the county courts, and referrals from other participants. Care was made to select the separated and comparison group (henceforth referred to as the "married group") with children of similar ages and from similar socioeconomic circumstances, by using the same sources of recruitment for each group (with the exception of the county court). The mean ages were: for the infants of separated families 22.45 months $(S D=10.24)$, the infants of married families 21.5 months $(S D=7.72)$, while those of the older siblings were 50 months $(S D=16.52)$ and 48.63 months $(S D=11.24)$ for the separated and married samples respectively. There were 11 infant boys with older brothers, 7 infant boys with older sisters, 12 infant girls with older brothers, and 14 infant girls with older sisters. The distribution of these pairs was relatively even across the separated and married groups ( 11 older brothers and 9 older sisters in separated families; 12 older brothers and 12 older sisters in married families). Social class (based on the Hollingshead Four-Factor Index of Social Prestige) ranged from 11 to 66. As is commonly found in studies of these families, the Hollingshead rating of separated families was lower than those of the married families (means $=32.95$ for the separated and 44.21 for the married families).

\section{Procedure}

The observation procedure was developed from that described by Abramovitch et al. (1979). The sibling pairs were observed at home for two 1-hour periods approximately 1 week apart. Attempts were made to choose a time when they were likely to be playing together. The mother was told she could go about her normal routine and the observer would not interfere. The observer did not interact with the children and stated she was busy working if they tried to approach her. The interactions of both children and their mother were recorded, not just initiations and responses as measured by Abramovitch et al. In order to maintain high inter-rater reliability the infant was selected as the target and her/his interactions with mother and sibling were recorded.

Three behaviours were coded each time they were displayed by either child: (1) Positive Social - this involved verbal and physical social behaviours including request, praise, approval, comfort, reassurance, and physical affection; (2) Negative Social - this category consisted of verbal and physical negative behaviours including physical aggression, object struggle, command, insult, and disapproval; (3) Imitation - this was scored when one child duplicated an activity of the second child, within 10 seconds of the second person performing this activity. It was preceded by visual regard of that person's activity. In addition to the above behaviours scored for each child separately, a further category (4) Joint Play, was scored when the two children had their attention focused on the same object. Finally, the amount of time the infant spent in exploration or play by him/herself, (5) Solitary Play, was recorded to mark the time when both siblings were present but the infant was not interacting with anyone.

Data were stored on an Epson HX-20 computer using a program created by Felce, de Kock, and Repp (1986). Every act defined by one of the above categories was scored as a discrete event within the flow of the infant's activity and interactions. The duration of each behaviour and bout of joint play was also recorded, as the computer was programmed to measure its onset and termination. Some (e.g. a statement comforting the other) lasted for very brief moments, whereas others (e.g. a cuddle) might last for minutes. Thus, for each hour of observation both a frequency count of these behaviours and the duration of time the children spent engaged in any category was recorded, with the exception of imitation (frequency only). Although a few categories (see Results section and Footnote 1) were mutually exclusive, the others could co-occur. So, for example, a child might display positive bids while also engaged in joint play.

\section{Reliability}

Inter-rater reliability was assessed on six occasions, twice each before, during, and at the completion of data collection. The software by Felce et al. calculates an agreement between raters for each behaviour that is more conservative than other percentage ratings, such as those quoted below. Rather than summing totals, agreement is scored when one observer scored a behaviour as occurring within 5 seconds of the second observer recording it on the database. Reliability ranged from $65 \%$ at the start of the data collection period to $78 \%$ at the end of it. These latter estimates are similar to those obtained by other researchers of siblings; Abramovitch et al. (1979): $76.1 \%$, Lamb (1978b): 80\% (range 67-100), Dunn and Kendrick (1981): $84 \%$ (range 57-100).

\section{Results}

When one child left the room recording was stopped. This occurred on average 16.57 times per hour, and lasted for 15.7 minutes. The measures of interaction in each family were prorated to account for this. The mean scores of the sibling interaction measures are displayed in Tables 1 and 2. Table 1 shows the means (and standard deviations) for each of the six frequency scores, in terms of the number of occurrences per hour of observation (i.e. when the two children were present in the same room). Table 2 shows the same measure in terms of the number of minutes per hour in which the children were engaged in the activity. The left-hand column of Tables 1 and 2 show the (Pearson) correlations for each behaviour between each session (Time $1 \&$ Time 2). Table 1 shows that only the positive gestures between the siblings were consistent between sessions, whereas Table 2 shows that all the duration measures, except for the infrequent bouts of negative behaviour by the older sibling, were significant. As the frequency measures were unreliable (some, presumably, because of their low frequency) preliminary repeated analyses were conducted to examine the effects of the explanatory variables (described below) or interactions on each behaviour across the two sessions. As none was significant the data from the two sessions were pooled. 
Table 1

Correlations between Time 1 and Time 2 Sessions and Mean Scores (Standard

Deviations in Brackets) for Each of the Frequency Measures in the Two Marital Status

Groups: Occurrence per Hour

\begin{tabular}{lccc}
\hline & Time 1-Time 2 \\
Variable & Correlations & Garried & Separated \\
\cline { 3 - 4 } Infant positive & $.71^{* *}$ & $17.77(21.73)$ & $23.15(22.96)$ \\
Infant negative & .29 & $6.48(4.66)$ & $8.00(7.48)$ \\
Older sibling positive & $.67^{* *}$ & $36.50(27.58)$ & $31.02(27.16)$ \\
Older sibling negative & .28 & $10.25(6.98)$ & $11.97(7.92)$ \\
Joint play & .15 & $7.83(4.90)$ & $8.82(5.95)$ \\
Solitary play & .20 & $29.37(12.48)$ & $23.57(8.17)$ \\
\hline
\end{tabular}

${ }^{*} p<.05$ (two-tailed) ${ }^{* *} p<.01$.

Table 2

Correlations between Time 1 and Time 2 Sessions and Mean Scores (Standard

Deviations in Brackets) for Each of the Duration Measures in the Two Marital Status

Groups: Minutes Engaged per Hour

\begin{tabular}{lcrl}
\hline & $\begin{array}{c}\text { Time 1-Time 2 } \\
\text { Variable }\end{array}$ & Married & Separated \\
\cline { 3 - 4 } Correlations & $.71^{* *}$ & $1.39(1.71)$ & $9.71(12.43)$ \\
Infant positive & $.50^{* *}$ & $0.49(0.44)$ & $0.72(0.84)$ \\
Infant negative & $.65^{* *}$ & $3.50(3.45)$ & $3.57(3.83)$ \\
Older sibling positive & .24 & $0.71(0.64)$ & $0.83(0.61)$ \\
Older sibling negative & $.33^{*}$ & $6.62(6.02)$ & $8.67(9.16)$ \\
Joint play & $.42^{* *}$ & $50.98(5.01)$ & $46.08(9.13)$ \\
Solitary play & & &
\end{tabular}

${ }^{*} p<.05$ (two-tailed) $;{ }^{* *} p<.01$.

On average, in each hour the siblings engaged in 55 positive and 18 negative actions towards one another. These frequencies are marginally higher than those of Dunn and Kendrick (1982), who found that siblings engaged in 41 positive interactions and 25 negative ones, but it must be remembered that the children in this study were slightly older. Each observation session was characterised by periods in which the infant was engaged in solitary activity (compare the number of bouts in Table 1 with the high overall duration of this category in Table 2), punctuated by bouts of positive social interactions and less frequent negative encounters. Approximately $14 \%$ of the time was spent in joint play between the siblings.

\section{Statistical Analysis}

The high standard deviations in both tables show that over the 88 hours of observation the scores were not normally distributed. In addition some measures ${ }^{1}$ (e.g. solitary play and joint play) were necessarily not independent of one another (if you are playing alone you cannot be engaged in joint play with your sibling at the same time). The data were therefore not easily amenable

\footnotetext{
1 The computer program adapted for this study was modified to terminate some when others were initiated. The following were regarded as mutually exclusive: (a) positive and negative interaction from one sibling to the other-but one of these acts could quickly follow the other type; (b) joint play and solitary play with mother or sibling.
}

to standard parametric techniques like MANOVA, since these features of the data can generate artificially large group differences. The hypotheses were therefore tested using logistic regression techniques ${ }^{2}$ on the GLIM4 statistical package (Francis, Green, \& Payne, 1993). The aim was to examine the single and joint influence of the three predictor variables (Marital Status, Sex of Older Child, and Same- vs. Opposite-Sex pairs of siblings) upon each of the types of interaction measured (see Tables 1 and 2). The sample was relatively small and our main interest was (1) to examine sibling interaction in separated vs. nonseparated families and (2) to compare the two hypotheses concerning the sex of older siblings vs. pairs of siblings. Therefore, we concentrate our analyses on main effects and two-way interactions, mentioning threeway interactions only in brief.

Before the analyses were conducted checks were made to see if factors unrelated to the aims of the study might

\footnotetext{
2 The occurrence of each of the frequency measures over the 2 hours of observation was examined by declaring the error structure as a the Poisson distribution and the link function to be the log of scores - thus allowing for a wide range of scores and a high proportion of low or zero scores (see McCullagh \& Nelder, 1989). For the duration measures we examined the number of minutes per hour of observation in which the behaviour occurred. Thus the error structure was declared as binomial (occurrence vs non-occurrence) with the parameter $n$ set equal to 60 (i.e. the number of minutes per hour) and the link function as the logit.
} 
influence its results. Analyses were performed upon the dependent measures to be described below on two factors that could not be completely controlled for in collecting the sample: socioeconomic status (SES; as measured by the Hollingshead Index) and the age of the infant. Preliminary analyses showed that SES was not related to the frequency or duration of sibling interactions, but the age of the infant was. For both the frequency and duration measures each explanatory variable was treated as a two-level factor (married vs. separated; older brother vs. older sister; same- vs. opposite-sex pairs) and was fitted after the continuous covariate "age of infant". In all the analyses of sibling interaction that follow age was positively related to the frequency and duration of negative and positive interaction and also joint play. The Appendix shows how all the logistic regressions were constructed by fitting individual measures followed by combinations, in models that allow for covariance between explanatory variables.

\section{Positive Interaction in the Infant}

We first discuss the four measures of positive interaction between siblings. The first part of the Appendix (labelled [1]) shows the effects of the explanatory variables upon the frequency measure "Infant Positive Social". It displays the deviance of the null model $(a)$ and the deviances when each explanatory variable is included individually in the model $(b)$. The importance of an explanatory variable is demonstrated by the change in deviance that results from including it in the model relative to the change in degrees of freedom (model parameters).

Two calculations can be made. First, on including a variable, the change in deviance essentially follows the chi-square distribution, allowing us to test the significance of that variable. Second, the strength of the change in deviance can be assessed by dividing it by the scaled deviance of the null model, giving $\mathrm{R}^{2}$ (see the right-hand column in the Appendix). So, the first row in [1b] shows that infant age produced a highly significant change in deviance $\left[\chi^{2}(1,44)=1796.5-1483.8=312.7, p<.001\right]$, which when divided by the scaled deviance of the null model $(312.7 / 1796.5)$ produced an $\mathrm{R}^{2}$ of .174 . The remaining calculations show the effects of including individual variables into the model once the $17 \%$ of the predicted variance accounted for by age was taken into account. Thus the second row of $[1 b]$ shows that the factor marital status exerted a significant change in deviance, but calculation of the $\mathrm{R}^{2}$ indicated that the effect was very small (.008). Such a result shows the importance of calculating both the figures $\left(\chi^{2}\right.$ and $\left.\mathrm{R}^{2}\right)$ in order to measure the impact of an explanatory variable.

The two other explanatory variables were each significant and accounted for more variance than marital status. Including each variable separately does not take into account covariance or interactions. The next aim was to construct a multivariate model that produced the greatest change in scaled deviance with the smallest number of model parameters. Therefore the variable "Same vs. Opposite Sex Pairs" was added to the most powerful individual predictor, the variable "Sex of Older Sibling" [fitted after "Age of Infant"]. Section [1c] of the
Appendix shows that Same vs. Opposite Sex Pairs adds significant independent change in deviance even when the variance of the first two variables is taken into account $\left[\chi^{2}(1,44)=1355.8-1301.3=54.52\right]$. The interaction between the two variables was added next and found to be significant $\left[\chi^{2}(1,44)=1301.3-1136.6=164.70\right]$.

A new variable, Sibling Constellation, was then constructed to examine the interaction (Sex of Older Sibling $\times$ Same vs. Opposite Pairs) further. This had four levels to cover all the pairings (boy-boy, boy-girl, girl-boy, and girl-girl). This single factor produced the same change in deviance as the model in [1d] (a total $\mathrm{R}^{2}$ of .21 over and above the .174 accounted for by age) and also a different parameter estimate for each level. From this output it is possible to conduct pairwise comparisons between different levels of a factor using Wald's test (Dobson, $1990)^{3}$. In the 14 girl-girl pairs (mean $=30.17$ bids per hour) the infants exhibited more positive social interaction than pairs with an older boy (mean $=18$ for each), who in turn scored higher than the pairs with an older girl and a younger boy (mean $=7$ ) (in all cases Wald test $p<$ .01 , two-tailed). However, Marital Status and the Sibling Constellation $\times$ Martial Status interaction added significant change in deviance to the model (see [1e] and [1 $f]$ of the Appendix). Infants in separated families made over five more positive bids than those in married families (see Table 1), the interaction caused by infants in the five boyboy pairs in separated families exhibiting over twice as many bids as those in married families ( 27.2 vs. 10.83 : Wald test $p<.001)$. So, infants in girl-girl pairs throughout the sample and also boy-boy pairs in separated families made more positive bids.

Section 2 of the Appendix shows the analyses of the duration measure of infant positive interaction. Section $[2 b]$ reveals that the sex of the older child was not significant, whereas Same vs. Opposite Sex Pair and, particularly, Marital Status exerted a significant change in deviance (the $\mathrm{R}^{2}$ figures being respectively .03 and .295). As Table 2 shows, infants from separated families spent over seven times as long in positive interaction with their siblings as did their counterparts from married families. Sections $[2 c]$ and $[2 d]$ of the Appendix also show that the factor Same vs. Opposite Sex continued to account for a significant though smaller amount of the variance $[2 c]$ when added to Marital Status, although the interaction was not significant $[2 d]$. Infants in same-sex pairs spent longer in positive interaction $($ mean $=6.38$ minutes per hour vs. 3.56 for opposite-sex pairs). Taken together Marital Status and Same vs. Opposite Sex accounted for $34 \%$ of the predicted variance.

\section{Positive Interaction in the Older Sibling}

Section 3 of the Appendix shows the analysis of the frequency of the older child's positive bids. Section [3b] shows that all four predictors (including the covariate

\footnotetext{
${ }^{3}$ Wald's test calculates $t$ by dividing the difference between two parameter estimates in a model without the automatic intercept by the standard error of this difference:

$$
t=\frac{\text { Parameter Estimate } 1-\text { Parameter Estimate } 2}{\sqrt{\text { Variance } 1+\text { Variance } 2-(2 \times \text { Covariance })}}
$$
}


infant age) were significant, but Sex of Older Child accounted for far more variance. Girls engaged in almost twice as many social bids to their younger siblings than did boys (respectively 44 per hour vs. 25 per hour-a difference that accounted for $22.2 \%$ of the predicted variance). As sections [3c] and [3d] of the Appendix show, the addition of Same Sex vs. Opposite Sex to the model with Age of Infant and Sex of Older Child already fitted produced a significant main effect and interaction (Sex of Older Child $\times$ Same vs. Opposite Sex pair), accounting for an additional $8 \%$ of the variance. Further analyses were performed to tease apart the Sibling Constellation variable (as above). Wald tests showed significant differences between each group: girls with younger sisters carried out more social bids (52.28 per hour) followed by girls with younger brothers (27.57 per hour), boys with younger brothers (25.79 per hour), and boys with younger sisters $(23.82$ per hour) (all $p<.01$ ). As sections [3e] and [3f] show, Marital Status and the Sibling Constellation $\times$ Marital Status interactions were significant when added to the model depicted in [3d]. As Table 1 shows, children from married families made more bids, but this was because older brothers in opposite-sex pairs in separated families exhibited so few (14.42 per hour vs. 37.17 for such children in married families: Wald test $p<.001)$.

The duration measures of older siblings' positive interaction are shown in section 4 of the Appendix. As with the frequency measure, the highest proportion of the variance was accounted for by the variable Sex of Older Sibling $\left(\mathrm{R}^{2}=.255\right)$, with only Same vs. Opposite Sex also being significant. When the latter variable was added to the former, the main effect [4c] and interaction [4d] produced a significant change in deviance adding, respectively, $2.9 \%$ and $7.4 \%$ to the effect of Sex of Older Sibling. Older girls spent significantly longer (Wald test $p<.01$ in each case) in positive social interaction with their younger sisters (6.17 minutes) than all the other pairs (2.48 minutes for older sister-younger brother pairs; 2.45 for older brother-younger sister pairs; 2.04 minutes for older brother-younger sister pairs).

\section{Joint Play}

Sections 5 and 6 of the Appendix show the frequency and duration of joint play between the siblings. When the separated and married families were compared, the frequency of joint play episodes was similar, but pairs in separated families played together for 2 minutes longer per hour (see Table 2). Logistic regressions similar to those carried out above showed that for both the duration and the frequency measures there were significant main effects for Sex of Older Child and Same vs. Opposite Sex effects and a significant interaction, accounting for $27.4 \%$ and $30.9 \%$ of the total variance in the frequency and duration measures. When the Sibling Constellation measure was examined, older sisters spent significantly longer (Wald test $p<.01$ in all cases) in joint play with younger sisters (21 bouts for 11.51 minutes per hour) than did the other groups (11.74 bouts for 5.16 minutes per hour). However, these patterns were qualified on the duration analyses by added main effects of Marital Status and a Sibling Constellation $\times$ Status interaction $[6 e, 6 f]$, largely because the girl-girl pairs in separated families spent twice as long in joint play than did all other pairings (16 minutes vs. 3-9 minutes for all others: $p<.01$ ).

\section{Infant Solitary Play}

Section 7 of the Appendix summarises the logistic regression data for the measure duration of solitary play per hour. All the variables independently contributed a significant change in scaled deviance to the null model, the strongest individual predictor being Marital Status (accounting for $9.5 \%$ of the predicted variance in solitary play). As Table 2 shows, the infants in married families spent almost 4 minutes longer per hour in solitary play. When the next highest individual predictor, Same vs. Opposite Sex, was added to the model, this contributed a further $10 \%$ of unique variance. That infants in oppositesex pairs spent 5 minutes longer per hour in solitary play (51.8 in opposite vs. 46.22 in same-sex pairs) was explained by same-sex pairs playing alone for 10 minutes less in separated families (42.38 minutes vs. $>50$ for all other configurations: Wald tests $p<.01$ in each case).

\section{Negative Interaction in the Infant and Older Child}

Table 1 shows that infants engaged in approximately 7 negative bouts of interaction, whereas the older children engaged in 11. However, Table 2 shows that the siblings demonstrated such actions for less than 1 minute over the course of each hour of observation. The logistic regressions showed no effects of the three predictor variables upon the durations of such actions for either child. For the two frequency measures the same effects were evident, and we will only report the measure for the older child here. As section 8 of the Appendix shows, the strongest single predictor was Sex of Older Child $\left(\mathrm{R}^{2}=\right.$ $.08)$. Marital Status contributed $1 \%$ additional variance but the interaction was not significant. In short, older sisters performed more negative acts (mean $=12.89$ per hour vs. 9.23 for older brothers) as did children from separated families (mean $=11.97$ vs. 10.25 for children in married families).

\section{Imitation between the Siblings}

Imitation was absent in $15(34 \%)$ of the older siblings and $11(25 \%)$ of the younger ones. These data were examined in terms of whether or not the children engaged in any acts of imitation. Neither Sex of Older Child nor Same vs. Opposite Sex revealed differences in the occurrence of imitation in either child. Marital Status had no effect upon the occurrence of infant imitation. However, twice as many older siblings in the separated families imitated the infant $(18 / 20=90 \%)$ than married families $\left[11 / 24=45 \%: \chi^{2}(1,44)=9.5, p<.005\right]$.

\section{Influence of Maternal Presence on Sibling Interaction}

It is important to consider whether the patterns of sibling interaction reported here are the product of external factors like the setting in which they interact and possible stage managing by the mother. The married 
families lived in larger properties and were significantly more likely to be home owners: $100 \%$ vs. $45 \%$ of the separated sample (Fisher's Exact Test $=13.58, p<.001$, 2 -tailed). Given that some of the separated families lived in one- or two-room dwellings there was less opportunity for the mother to leave the room, even though she was instructed to go about her usual activities. Thus it is not surprising that married mothers left the room more often per hour (20 times vs. 13 for separated mothers) and were out of the room for longer (18.81 minutes vs. 14.14 for separated mothers).

To examine how maternal behaviour influenced the sibling interactions, two groups of logistic regression were performed. Firstly, the same 2 (Marital Status) $\times 2$ $($ Sex of Older Child) $\times 2$ (Same vs. Opposite Sex) logistic regression analyses were conducted (with Infant Age as a covariate) on the frequencies and durations of four aspects of mother-infant interaction: infant positive and negative to mother and mother positive and negative to infant. We report here only the best fit models of these variables. On the frequency measure mother positive to infant, the variable Sibling Constellation (i.e. the Same vs. Opposite Sex $\times$ Sex of Older Child interaction) was the strongest predictor (scaled deviance of null model $=$ 928.48: Additive change in deviance, $\chi^{2}=146.3$ (Infant Age) $+110.6 \quad$ [Sibling Constellation] $+12.8 \quad$ [Status]). Wald tests $(p<.01)$ showed that mothers made fewer bids to girls with older sisters (44.75 per hour) than girls with older brothers (54.14 per hour), and that women in both these groups made fewer than those to infant boys with older sisters (67.54 per hour) and brothers (68.77 per hour). After Sibling Constellation, Marital Status added a small but significant change in deviance $\left(\mathrm{R}^{2}=.014\right)$. Mothers made almost five more bids to infants in married families (60.02 per hour vs. 55.37 in separated families). On the duration of their positive interaction there was a single main effect for Sex of Older Sibling $\left(\mathrm{R}^{2}=.041\right)$, with longer maternal bids to infants with older brothers (11.4 minutes per hour vs. 8.77 minutes in families with an older sister: scaled deviance of null model $=145 ; \chi^{2}=$ .11 [Infant Age] + 5.91 [Sex of Older Sibling])

An interaction of all the predictors accounted for the most change in deviance in the frequency measure mother negative to infant, with Marital Status $\left(\mathrm{R}^{2}=.22\right)$ accounting for most of the change, followed by Sibling Constellation $\left(\mathrm{R}^{2}=.14\right)$ and the interaction $\left(\mathrm{R}^{2}=.08\right)$ : (scaled deviance of null model $=756.54 ; \chi^{2}=21.72$ [Age] + 168.5 [Martial Status]+102.9 [Sibling Constellation] +63.10 [Status $\times$ Sibling Constellation]). Separated mothers displayed twice as many negative acts to their infants (15.18 per hour vs. 7.09 for married mothers), but this difference was accounted for by the six mothers to girls with older brothers $(27.9$ per hour vs. $<14$ for all other groups). For the duration measure of mother negative to infant, both Marital Status $\left(\mathrm{R}^{2}=.25\right)$ and Same vs. Opposite $\operatorname{Sex}\left(\mathrm{R}^{2}=.1\right)$ were significant as individual predictors - the interaction did not contribute to a change in deviance (scaled deviance of null model $=$ 43.803; $\chi^{2}=.08455[$ Age $]+11.05[$ Status $]+4.21$ [Same vs. Opposite Sex]). Mothers engaged in three times more negative interaction in separated families (1.21 minutes per hour vs. 0.42 minutes for married mothers). Likewise mothers exhibited almost twice as much negative be- haviour to opposite-sex pairs (1.07 minutes per hour vs. 0.56 minutes to same-sex pairs).

Analyses of the frequency measure infant positive to mother revealed small but significant independent change in deviance scores for Sex of Older Sibling $\left(\mathrm{R}^{2}=.06\right)$ and Marital Status $\left(\mathrm{R}^{2}=.003\right)$, and no interaction (scaled deviance of null model $=1651.4 ; \chi^{2}=612.2[$ Age] + 99.43 [Sex of Older Child] + 5.77 [Marital Status]). In opposite-sex pairs infants made twice as many positive gestures per hour (51.75 per hour vs. 26.78 for those in same-sex pairs) and infants in separated families made five more per hour $(41.99$ vs. 36.55 for infants in married families). For the similar duration measure only Marital Status $\left(\mathrm{R}^{2}=.04\right)$ was significant once the large effect of Infant Age was controlled (scaled deviance of null model $=120.72 ; \chi^{2}=49.02$ [Age] + 5.08 [Marital Status]). Infants in separated families spent almost 2 minutes longer per hour in positive interaction (5.37 minutes per hour vs. 3.62 for those in married families).

On the frequency measure infant negative to mother, Sibling Constellation was the best predictor, accounting for $8 \%$ of the predicted variance (scaled deviance of null model $=457.16 ; \chi^{2}=0.11[$ Age $]+36.84$ [Sibling Constellation]), with Wald tests ( $p<.05$ in all cases) showing that girls with older brothers displayed fewer negative acts (8.64 per hour) than all the other children (means $>$ 10 per hour). The duration of infant's negative behaviour to their mothers was for 1.47 minutes per hour. There were no change in deviance caused by any predictor variable on this measure.

The second set of analyses conducted using the motherinfant data was to examine whether they had any bearing or influence upon the sibling interactions. The models of sibling interaction described above were reconstructed twice, once with the same mother-infant interaction measure loaded as a covariate (e.g. frequency of motherinfant positive interaction loaded before the predictors of the frequency of sibling-infant positive bids). The second time a variable of total mother-infant interaction (with positive and negative bids added) was loaded first. In neither set of analyses did the inclusion of the motherinfant variable influence the structure or significance of the models displayed in the Appendix. We may conclude that the patterns displayed in the Appendix do not seem to be a result of maternal stage-managing.

\section{Discussion}

The results of this study allow us to re-examine the two pairs of contrasting hypotheses described in the Introduction. On the issue of the sex of the sibling dyads, they suggest that in interactions between preschoolers the sex constellation of the pairs is more complex than previous analyses have suggested. For example, in samesex pairs the infants spent almost twice as long making positive gestures toward their older siblings. Similarly older sisters, irrespective of the sex of the younger child, engaged in more bids of positive interaction. However, the central factor in these analyses concerns the interaction between these two factors. The 14 sister-sister pairs seemed to interact more, and more richly, than the other 30 pairs. Such a conclusion is supported in both the frequency and duration measures of interaction. In 
sister-sister dyads there were twice as many bids of joint play lasting twice as long, the frequency of positive bids by both children was significantly higher, and older sisters spent longer in interaction with infant girls.

On the second issue under examination in this study, comparing the two marital status groups, the results show slightly but significantly more interaction between siblings in separated families than in married controls. In the separated families the infants played on their own less and engaged in positive interaction for much longer (seven times more, with an $\mathrm{R}^{2}$ of .295: see section [2] of the Appendix) periods per hour of observation, whereas the older siblings were more likely to engage in imitation of the younger ones. There was also a greater incidence of negative interaction between the siblings in separated families and in all pairs with older sisters. These latter findings must be qualified by two factors: (1) the nonsignificant and very low durations of negative interaction per hour: the children spent less than 1 minute per hour in such interaction; (2) the overall changes in deviance were low. It may well be the case that older sisters interact more with their younger siblings, so more negative interaction is a natural consequence of closeness rather than hostility.

How do the two issues of life stresses and the sex configuration of the sibling pairs relate to one another? Four of the findings support the belief that it is under conditions of stress that the patterns of sibling interaction, reported above, become accentuated. First, in separated families sister-sister pairs spent at least twice the time in joint play together than any other group. Pairs with older girls appear to maintain or increase a high degree of interaction with their siblings, particularly in girl-girl pairs, after parental separation. That older sisters are particularly sensitive to their siblings when the need arises has resonance with the findings of Ross and Milgram (1982) with adult siblings using self-report methods. Second, the infants in same-sex pairs within separated families spent much less time in solitary activity. Third, older brothers in opposite-sex pairs within separated families were significantly less prosocial, at least in the frequency of their bids. Fourth, regarding the tendency for same-sex pairs to engage in more positive interaction, it was further observed that boy-boy dyads in separated families made more bids than any other pairing other than girl-girl dyads. These last three findings suggest that same-sex relationships withstand, or even compensate for, the difficulties of events like parental separation.

Finally, the analyses of mother-infant interaction served to show primarily that the patterns of sibling interaction reported here are not simply a reflection of the ways in which mothers in different types of family organise activities while an observer is present. This was shown in the failure of the mother-infant measures to influence the sibling interactions. Indeed, some patterns seem to complement but not to influence one another. Just as sister-sister interaction was more in evidence, infant girls with older sisters received fewer positive bids from their mothers and mothers interacted more with children who had older brothers. Such complementarity has been found in previous research. A study of older sibling interaction by Bryant and Crockenberg (1980) found that interaction between sisters was negatively related to maternal responsivity to their daughters. Other patterns seem to suggest that high frequencies in the sibling pairs were echoed in the mother-infant interaction. For example, the durations of infant bids to mother and sibling were both greater in separated families, as were the amounts of negative interaction.

Are older sisters and particularly girl-girl pairs more sociable? It may simply be that girls are socialised to become nurturant and caring, and that the presence of infant siblings provides them with the opportunity to display these qualities. This possibility is raised by Abramovitch et al. (1979), Dunn and Kendrick (1982), and Lamb (1967a). Two reservations must be considered. In the first place a greater incidence within the global categories of interaction reported here might not signify enhanced sensitivity on the part of older girls. They played with their siblings more, but older sisters were also more negative to their younger siblings. Quality of interaction is difficult to assess. Lamb (1978a), for example, found that older brothers touched their siblings more than did older sisters. This might suggest that boys approach their siblings in ways that are different from, or complementary to, the styles of girls. However, the greater amount of solitary activity in pairs with an older brother suggests at the very least that dyads with older sisters devote more time to interacting with one another, so we may conclude that the analytic system here demonstrated more social bids by girls to their younger siblings, which has to be explained.

Second, it may be that the significance of these differences between older boys and girls might not be straightforward. Perhaps the extended contact in older sister dyads is not an indication of harmonious sibling ties? In his observations of sibling pairs in a setting equivalent to the Strange Situation, Stewart (1983, p. 197) noted that older girls might be excessive in the attention they lavish: "older sisters appeared to smother their younger brothers with far more care than was solicited". Given that there were no signs of excess in the older sisters' actions, that indeed it was their younger sisters who were the focus of the older girls' attentions and that the latter reciprocated, we may conclude that the evidence presented here shows more sensitive interaction by older sisters.

The greater amounts of positive interaction and joint play in children from separated families contrasts with findings on sibling relationships in older dyads, which suggest greater conflict (Hetherington, 1988; MacKinnon, 1989). Again it is worth considering factors that might complicate our interpretation of these results. It might be that the patterns witnessed here do not demonstrate enhanced interactions. For a start, the greater imitation in the older children from separated families is not typical. In Dunn and Kendrick's (1982) study of siblings, it was the younger ones who tended to imitate after age 1 year. Yet here the findings match other divorce research where the child aged 4 was the younger sibling, in that parental separation was associated with a rise in imitation (Summers et al., 1993). It could be that such behaviours are regressive symptoms of 4-year-olds that result from family dissolution. Alternatively, it may be that sensitive older siblings imitate their younger siblings as a means of teaching or simply communicating with them. It is not 
possible to make a judgement on this issue. Imitation is usually taken to be a sign of interest in preschoolers' interactions (Abramovitch et al., 1979), so it might well be a sign of the interest that older children show in their 2-year-old siblings.

Another intriguing finding is that it was younger children in the separated families who spent longer engaging in positive gestures towards their older siblings. It is more common for older children in sibling dyads to take the initiative. However, this finding should be put into context. In married families the younger children reciprocated their older siblings' bids less than half the time, whereas in separated families their increased positive gestures may be seen as part of an enriched pattern of interaction. When coupled with the results that indicate less solitary play by infants in separated families, the increase in positive bids suggests that when faced by stressful circumstances sibling relationships adapt for greater interaction - the older child by showing sensitivity to the younger one's contribution to play and the younger child in making longer social bids and less solitary activity.

In older children, sibling relationships do often manifest the conflicts that have been apparent in families. Yet Jenkins (1992) points out that some dyads remain (or become) very close in the face of family adversity. Indeed, these children manifest fewer signs of disturbance. In this sample of younger children there was no sign of emotional turmoil in the separated sample, which may have been witnessed in increased agonism between siblings. It seems likely, therefore, that preschool children are somewhat protected against the effects of marital dissolution, perhaps partly as a result of their sociocognitive immaturity (Rutter, 1989). Only longitudinal research will enable us to discern whether the extra sibling contact in the separated group or in pairs with an older sister has an influence on each child's development. The results reported here suggesting greater closeness in sister-sister pairs match those of recent research by Dunn, Slomkowski, and Beardsall (1994), which demonstrated both similar patterns in older sibling relationships after negative life experiences and continuity in sibling relationships over the course of childhood.

Acknowledgements - The authors wish to thank Judy Dunn for commenting upon an earlier draft of this paper, two anonymous reviewers who made very constructively critical comments upon the first submission of this paper, and, particularly, the many people who helped us in recruiting and the families who participated. We are also grateful to the Department of Psychology, University of Reading, where this research was conducted.

\section{References}

Abramovitch, R., Corter, C., \& Lando, B. (1979). Sibling interaction in the home. Child Development, 50, 997-1003.

Abramovitch, R., Corter, C., \& Pepler, D. J. (1980). Observations of mixed-sex sibling dyads. Child Development, 51, 1268-1271.

Abramovitch, R., Pepler, D., \& Corter, C. (1982). Patterns of sibling interaction among preschool-age children. In M. E. Lamb \& B. Sutton-Smith (Eds.), Sibling relationships: Their nature and significance across the lifespan. Hillsdale, NJ: Lawrence Erlbaum.
Bank, S. P., \& Kahn, M. D. (1982). The sibling bond. New York: Basic Books.

Beal, E. W. (1979). Children of divorce: A family systems perspective. Journal of Social Issues, 35, 140-154.

Boer, F., \& Dunn, J. (1992). Children's sibling relationships: Developmental and clinical issues. Hillsdale, NJ: Lawrence Erlbaum.

Brody, G. H., \& Stoneman, Z. (1987). Sibling conflict: Contributions of the siblings themselves, the parent-sibling relationship, and the broader family system. Journal of Children in Contemporary Society, 19, 39-53.

Bryant, B. K., \& Crockenberg, S. B. (1980). Correlates and dimensions of prosocial behavior: A study of female siblings and their mothers. Child Development 51, 529-544.

Cicirelli, V. G. (1994). Sibling relationships in cross-cultural perspective. Journal of Marriage and the Family, 56, 7-20.

Corter, C., Pepler, D., \& Abramovitch, R. (1982). The effects of situation and sibling status on sibling interaction. Canadian Journal of Behavioral Science, 14, 380-392.

Dobson, A. (1990). An introduction to generalised linear models. London: Chapman \& Hall.

Downey, D. B., \& Powell, B. (1993). Do children in singleparent households fare better with same sex parents? Journal of Marriage and the Family, 55, 55-71.

Dunn, J. (1983). Sibling relationships in early childhood. Child Development, 54, 787-811.

Dunn, J., \& Kendrick, C. (1979). Interaction between young siblings in the context of family relationships. In M. Lewis \& L. D. Rosenblum (Eds.), The child and its family. New York: Plenum Press.

Dunn, J., \& Kendrick, C. (1981). Social behavior of young siblings in the family context: Differences between same-sex and different-sex dyads. Child Development, 52, 1265-1273.

Dunn, J., \& Kendrick, C. (1982). Siblings: Love, envy, and understanding. Cambridge, MA: Harvard University Press.

Dunn, J., Slomkowski, C., \& Beardsall, L. (1994). Sibling relationships from the preschool period through middle childhood and early adolescence. Developmental Psychology, 30, 315-324.

Dunn, J., Slomkowski, C., Beardsall, L., \& Rende, R. (1994). Adjustment in middle childhood and early adolescence: Links with earlier and contemporary sibling relationships. Journal of Child Psychology and Psychiatry, 35, 491-504.

Engfer, A. (1988). The interrelatedness of marriage and the mother-child relationship. In R. A. Hinde \& J. StevensonHinde (Eds.), Relationships within families: Mutual influences. Oxford: Clarendon Press.

Felce, D., de Kock, U., \& Repp, A. C. (1986). An ecobehavioral analysis of small community-based houses and traditional large hospitals for severely and profoundly mentally handicapped adults. Applied Research in Mental Retardation, 1, 393-408.

Francis, B., Green, M., \& Payne, C. (Eds.) (1983). The GLIM system release 4 manual. Oxford: Oxford University Press.

Freud, A., \& Dann, S. (1951). An experiment in group upbringing. Psychoanalytic Study of the Child, 6, 127-168.

Hetherington, E. M. (1988). Parents, children, and siblings: Six years after divorce. In R. A. Hinde \& J. Stevenson-Hinde (Eds.), Relationships within families: Mutual Influences. Oxford: Clarendon Press.

Hetherington, E. M., Clingempeel, W. G., Anderson, E. R., Deal, J. E., Hagan, M. S., Hollier, E. A., \& Linder, M. S. (1992). Coping with marital transitions. Monograph of the Society for Research in Child Development, 57, (serial no. 227).

Hetherington, E. M., Cox, M., \& Cox, R. (1979). The development of children in mother-headed families. In D. Reiss \& H. A. Hoffman (Eds.), The American family: Dying or developing. New York: Plenum Press. 
Hetherington, E. M., Cox, M., \& Cox, R. (1982). Effects of divorce on parents and children. In M. E. Lamb (Ed.), Nontraditional families: Parenting and child development. Hillsdale, NJ: Lawrence Erlbaum.

Jenkins, J. M. (1992). Sibling relationships in disharmonious homes: Potential difficulties and protective effects. In F. Boer \& J. Dunn (Eds.), Children's sibling relationships: Developmental and clinical issues. Hillsdale, $\mathrm{NJ}$ : Lawrence Erlbaum.

Kier, C. A., \& Fouts, G. T. (1989). Sibling play in divorced and married-parent families. Journal of Reproductive and Infant Psychology, 7, 139-146.

Kier, C. A., \& Lewis, C. (1997). Infant-mother attachment in separated and married families. Journal of Divorce and Remarriage 26, 185-194.

Kimball, W. H., Stewart, R. B., Conger, R. D., \& Burgess, R. L. (1980). A comparison of family interaction in singleversus two-parent abusive, neglectful, and control families. In T. M. Field, S. Goldberg, D. Stern, \& A. M. Sustek (Eds.), High-risk infants and children. New York: Academic Press.

Lamb, M. E. (1978a). The development of sibling relationships in infancy: A short-term longitudinal study. Child Development, 49, 1189-1196.

Lamb, M. E. (1978b). Interactions between 18-month-olds and their preschool-aged siblings. Child Development, 49, 51-59.

Lamb, M. E., \& Sutton-Smith, B. (Eds.) (1982). Sibling relationships: Their nature and significance across the lifespan. Hillsdale, NJ: Lawrence Erlbaum.

MacKinnon, C. E. (1989). An observational investigation of sibling interactions in married and divorced families. Developmental Psychology, 25, 36-44.

McCullagh, P., \& Nelder, J. A. (1989). Generalised linear models (2nd edn.). London: Chapman \& Hall.

Robson, B. (1979). My parents are divorced, too. Toronto: Dorset Publishing Co.

Rohrlich, J. A., Ranier, R., Berg-Cross, L., \& Berg-Cross, G. (1977). The effects of divorce: A research review with a developmental perspective. Journal of Clinical Child Psychology, 6, 15-20.
Ross, H. G., \& Milgram, J. I. (1982). Important variables in adult sibling relationships: A qualitative study. In M. E. Lamb \& B. Sutton-Smith (Eds.), Sibling relationships: Their nature and significance across the lifespan. Hillsdale, NJ: Lawrence Erlbaum.

Rutter, M. (1989). Pathways from childhood to adult life. Journal of Child Psychology and Psychiatry, 30, 23-51.

Schlesinger, B. (1982). Children's viewpoints of living in a oneparent family. Journal of Divorce, 5, 1-23.

Springer, C., \& Wallerstein, J. S. (1983). Young adolescents' responses to their parents' divorces. In L. A. Kurdek (Ed.), Children and divorce. San Francisco, CA: Jossey-Bass.

Stewart, R. B. (1983). Sibling attachment relationships: Childinfant interactions in the strange situation. Developmental Psychology, 19, 192-199.

Stewart, R. B., \& Marvin, R. S. (1984). Sibling relations: The role of conceptual perspective-taking in the ontogeny of sibling care giving. Child Development, 55, 1322-1332.

Stolberg, A. L., \& Anker, J. M. (1983). Cognitive and behavioral changes in children resulting from parental divorce and consequent environmental changes. Journal of Divorce, 7, 23-41.

Summers, M., Summers, C. R., \& Ascione, F. R. (1993). A comparison of sibling interaction in intact and single-parent families. Journal of Divorce and Remarriage, 20, 215-227.

Teti, D. M., \& Ablard, K. E. (1989). Security of attachment and infant-sibling relationships: A laboratory study. Child Development, 60, 1519-1528.

Troyer, W. (1979). Divorced kids. Toronto: Clarke, Irwin, \& Co.

Wallerstein, J. S., \& Blakeslee (1989). Second chances. London: Corgi Books.

Weiss, R. S. (1979a). Growing up a little faster: The experience of growing up in a single-parent household. Journal of Social Issues, 35, 97-111.

Weiss, R. S. (1979b). Going it alone. New York: Basic Books.

Accepted manuscript received 7 April 1997

Appendix

\section{Patterns of Sibling Interaction, with Marital Status, Sex of Older Child and Same vs. Opposite Sex of Sibling Pairs as Explanatory Variables}

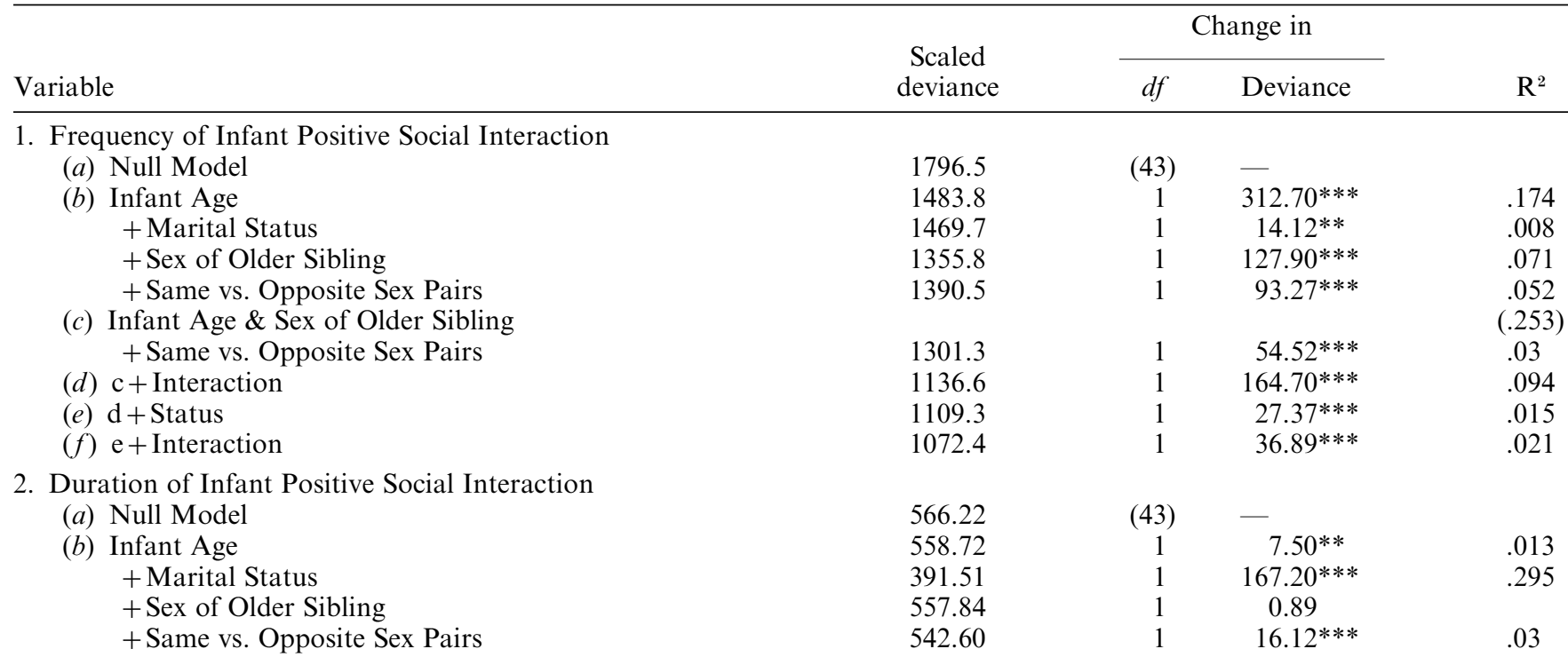


Appendix-(cont.)

\begin{tabular}{|c|c|c|c|c|}
\hline \multirow[b]{2}{*}{ Variable } & \multirow{2}{*}{$\begin{array}{c}\text { Scaled } \\
\text { deviance }\end{array}$} & \multicolumn{2}{|c|}{ Change in } & \multirow[b]{2}{*}{$\mathrm{R}^{2}$} \\
\hline & & $d f$ & Deviance & \\
\hline (c) Infant Age \& Marital Status & & & & $(.308)$ \\
\hline + Same vs. Opposite Sex Pairs & 370.37 & 1 & $21.37 * * *$ & .038 \\
\hline (d) $\mathrm{c}+$ Interaction & 368.85 & 1 & 1.28 & \\
\hline \multicolumn{5}{|c|}{ 3. Frequency of Older Sibling Positive Social Interaction } \\
\hline (b) Infant Age & 1571.9 & 1 & $64.25 * * *$ & .039 \\
\hline + Marital Status & 1546.9 & 1 & $24.59 * *$ & .015 \\
\hline+ Sex of Older Sibling & 1208.0 & 1 & $363.80 * * *$ & .222 \\
\hline + Same vs. Opposite Sex Pairs & 1476.3 & 1 & $95.60 * * *$ & .058 \\
\hline (c) Infant Age \& Sex of Older Sibling & & & & $(.261)$ \\
\hline + Same vs. Opposite Sex Pairs & 1177.7 & 1 & $30.31 * * *$ & \\
\hline (d) $\mathrm{c}+$ Interaction & 1085.5 & 1 & $92.19 * * *$ & .056 \\
\hline (e) $\mathrm{d}+$ Status & 1072.6 & 1 & $13.5^{* *}$ & .008 \\
\hline$(f) \mathrm{e}+$ Interaction & 945.6 & 1 & $124.4 * * *$ & .076 \\
\hline \multicolumn{5}{|l|}{ Duration of Older Sibling Positive Social Interaction } \\
\hline (a) Null Model & 136.96 & $(43)$ & - & \\
\hline (b) Infant Age & 133.14 & 1 & 3.82 & \\
\hline + Marital Status & 133.14 & 1 & 0 & \\
\hline+ Sex of Older Sibling & 98.19 & 1 & $34.95 * * *$ & .255 \\
\hline + Same vs. Opposite Sex Pairs & 122.40 & 1 & $10.74^{* *}$ & .078 \\
\hline (c) Infant Age \& Sex of Older Sibling & & & & $(.283)$ \\
\hline + Same vs. Opposite Sex Pairs & 94.260 & 1 & $3.93 *$ & .029 \\
\hline (d) $\mathrm{c}+$ Interaction & 84.06 & 1 & $10.20 * *$ & .074 \\
\hline \multicolumn{5}{|l|}{ Frequency of Joint Play Between Siblings } \\
\hline (a) Null Model & 266.34 & $(43)$ & - & \\
\hline (b) Infant Age & 257.62 & 1 & $8.72 * *$ & .033 \\
\hline + Marital Status & 256.06 & 1 & 1.56 & \\
\hline+ Sex of Older Sibling & 229.69 & 1 & $28.01 * * *$ & .105 \\
\hline + Same vs. Opposite Sex Pairs & 227.58 & 1 & $30.04 * * *$ & .113 \\
\hline (c) Infant Age \& Same vs. Opposite Sex Pairs & & & & $(.146)$ \\
\hline+ Sex of Older Sibling & 210.57 & 1 & $17.01 * * *$ & .064 \\
\hline (d) $\mathrm{c}+$ Interaction & 193.53 & 1 & $17.04 * * *$ & .064 \\
\hline \multicolumn{5}{|l|}{ 6. Duration of Joint Play Between Siblings } \\
\hline (a) Null Model & 319.08 & $(43)$ & - & \\
\hline (b) Infant Age & 285.15 & 1 & $33.93 * * *$ & .106 \\
\hline + Marital Status & 279.36 & 1 & $5.79 *$ & .018 \\
\hline+ Sex of Older Sibling & 263.05 & 1 & $22.10 * * *$ & .069 \\
\hline + Same vs. Opposite Sex Pairs & 262.36 & 1 & $22.79 * * *$ & .071 \\
\hline (c) Infant Age \& Same vs. Opposite Sex Pairs & & & & $(.177)$ \\
\hline+ Sex of Older Sibling & 248.36 & 1 & $14.06 * * *$ & .044 \\
\hline (d) $\mathrm{c}+$ Interaction & 220.15 & 1 & $28.21 * * *$ & .088 \\
\hline (e) $\mathrm{d}+$ Status & 212.33 & 1 & $7.82 * *$ & .031 \\
\hline$(f) \mathrm{e}+$ Interaction & 173.16 & 1 & $39.17 * * *$ & .155 \\
\hline \multicolumn{5}{|l|}{ 7. Duration of Infant Solitary Play } \\
\hline (a) Null Model & 252.88 & $(43)$ & - & \\
\hline (b) Infant Age & 209.66 & 1 & $43.22 * * *$ & .171 \\
\hline + Marital Status & 185.69 & 1 & $23.97 * * *$ & .095 \\
\hline+ Sex of Older Sibling & 193.38 & 1 & $16.27 * * *$ & .064 \\
\hline + Same vs. Opposite Sex Pairs & 185.95 & 1 & $23.71 * * *$ & .094 \\
\hline (c) Infant Age + Status & & & & $(.266)$ \\
\hline + Same vs. Opposite Sex Pairs & 160.17 & 1 & $25.52 * * *$ & .101 \\
\hline (d) $\mathrm{c}+$ Interaction & 156.14 & 1 & $4.03 *$ & .016 \\
\hline \multicolumn{5}{|l|}{ 8. Frequency of Sibling Negative to Infant } \\
\hline (a) Null Model & 422.61 & $(43)$ & - & \\
\hline (b) Infant Age & 422.50 & 1 & 0.11 & \\
\hline + Marital Status & 416.71 & 1 & $5.79 *$ & .014 \\
\hline+ Sex of Older Sibling & 388.86 & 1 & $33.63 * * *$ & .080 \\
\hline + Same vs. Opposite Sex Pairs & 419.90 & 1 & 2.60 & \\
\hline \multicolumn{5}{|l|}{ (c) Infant Age \& Sex of Older Sibling } \\
\hline + Marital Status & 381.82 & 1 & $7.05 * *$ & .017 \\
\hline (d) $\mathrm{c}+$ Interaction & 381.74 & 1 & 0.07 & \\
\hline
\end{tabular}

$* p<.05 ; * * p<.01 ; * * * p<.001$. 